\title{
THE INFLUENCE OF FREE-RADICAL CONCENTRATION ON THE SHEAR BOND STRENGTH OF DENTAL COMPOSITES
}

\author{
VPLIV KONCENTRACIJE PROSTIH RADIKALOV NA STRIŽNO \\ TRDNOST DENTALNIH KOMPOZITOV
}

\author{
Biljana Kiteska1, Nenad Funduk¹, Pavel Cevc², Adolf Jesih ${ }^{3}$, Alojz Anžlovar ${ }^{4}$, Igor Kopač ${ }^{1}$ \\ ${ }^{1}$ University of Ljubljana, Medical Faculty, Department of Prosthodontics, Hrvatski trg 6, 1000 Ljubljana, Slovenia \\ ${ }^{2}$ Jožef Stefan Institute, Solid State Physics Department, Jamova 39, 1000 Ljubljana, Slovenia \\ ${ }^{3}$ Jožef Stefan Institute, Department of Inorganic Chemistry and Technology, Jamova 39, 1000 Ljubljana, Slovenia \\ ${ }^{4}$ National Institute of Chemistry, Laboratory for Polymer Chemistry and Technology, Hajdrihova 19, 1000 Ljubljana, Slovenia \\ igor.kopac@mf.uni-lj.si
}

Prejem rokopisa - received: 2017-06-14; sprejem za objavo - accepted for publication: 2017-09-07

doi: $10.17222 / \mathrm{mit} .2017 .072$

\begin{abstract}
The aim of this study was to evaluate the influence of the free-radical concentration on the shear bond strength between a composite resin and self-adhesive composite cement. Filtek ultimate flowable restorative composite was used for the thin layer samples, which were analyzed using electron paramagnetic resonance (EPR). Rely-X-Unicem cement was applied to the disc-shaped samples and the shear bond strength and failure modes were analysed at weekly intervals. The concentration of the free radicals dropped to $10 \%$ after $24 \mathrm{~h}$. A value for the degree of conversion equal to $74 \pm 2 \%$ was achieved after $2 \mathrm{~d}$. The shear bond values were in the range from 25.5 $\pm 3.7 \mathrm{MPa}$ to $9.8 \pm 4.3 \mathrm{MPa}$ for four groups of samples, measured in four different time intervals. A high concentration of free radicals ensures reliable chemical bonding with a freshly applied cement in group 1 , while in the samples of group $2(7 \mathrm{~d})$, group $3(14 \mathrm{~d})$ and group $4(21 \mathrm{~d}$ of recombination in water), the potential of the free radicals was diminished.
\end{abstract}

Keywords: composite resin, free radicals, electron paramagnetic resonance, degree of conversion, shear bond strength, adhesion properties

Namen raziskave je bil proučiti vpliv koncentracije prostih radikalov na moč vezave med kompozitom in samostrjujočim se kompozitnim cementom. Kompozit Filtek ultimate flowable restorative smo uporabili za pripravo vzorcev v tanki plasti za meritve koncentracije prostih radikalov $\mathrm{z}$ elektronsko paramagnetno resonanco (angl. EPR). Na kompozitne diske smo nanesli kompozitni cement Rely-X-Unicem in v tedenskih intervalih merili moč vezave med obema materialoma. Koncentracija prostih radikalov se je v 24 urah zmanjšala na $10 \%$ začetne koncentracije. Stopnja konverzije (DC) se je po dveh dneh ustalila pri $74 \pm 2 \%$. Moč vezave med obema kompozitoma je bila v območju med 25,5 $33,7 \mathrm{MPa}$ in $9,8 \pm 4,3$ MPa za štiri skupine vzorcev. Visoka koncentracija prostih radikalov zagotavlja dobro kemično vezavo s sveže dodanim kompozitnim cementom, medtem ko je vpliv koncentracije prostih radikalov po $(7,14$ in 21) dneh rekombinacije zanemarljiv.

Ključne besede: kompozit, prosti radikali, elektronska paramagnetna resonanca, stopnja konverzije, strižna trdnost, adhezijske lastnosti

\section{INTRODUCTION}

In a daily practice, clinicians frequently need to apply a fresh layer of methacrylate-based composite over an already-existing and aged composite. This commonly happens in two main clinical situations: (a) when a selective repair, instead of the a complete replacement of a failed direct composite restoration is carried out, or alternatively, (b) when indirect restorations are adhesively cemented onto protected dentin according to the principles of the a dual dentin bonding or, as also named, the immediate dentin-sealing (IDS) technique. ${ }^{1,2}$

The chemical bonding of the composite resin matrices is formed by the unreacted methacrylate groups and/or the free radicals present in the underneath composite layer. ${ }^{3,4}$ The extent of the monomer-to-polymer conversion during the polymerisation process is expressed as the degree of conversion (DC) and can be studied by Raman spectroscopy, which measures the $\mathrm{C}=\mathrm{C}$ double bond's stretching vibrations on the compo- site surface. ${ }^{5,6}$ Consequently, the DC is directly related to the mechanical properties of the composites and their clinical performance. ${ }^{7,8}$

Free radicals are reactive chemical species with an unpaired electron. Their interactions promote the development and cross-linking of the polymer chains that create a solid unit. ${ }^{9}$ However, as the composite substrate ages, the free radicals decay over time. ${ }^{3}$ As a consequence, the tendency for chemical bonding with a freshly applied composite layer decreases. ${ }^{4}$ Although it has never been directly proven experimentally, several authors have speculated that the concentration of the active free radicals remaining in the underlying layer is an important factor when it comes to achieving sufficient bonding in the composite. ${ }^{3,4,10}$ However, there are other mechanisms described in the literature regarding the bonding between the layers of the same composite or different kinds of composite materials, such as a micromechanical bond or an interpenetrating polymer network matrix..$^{10,11}$ 
The most suitable method for studying free radicals in various materials is electron paramagnetic resonance (EPR) spectroscopy. The unpaired electrons localised at the free radicals serve as precise local probes at the molecular level, providing information about the nature of the free radicals, their intensity and evolution over time. ${ }^{12}$ The free radicals in methacrylate resin-based composites are well documented in the literature. ${ }^{9}$ The unpaired methacrylic electron is localized on the carbon atom and significantly overlaps with the protons of the nearest $\mathrm{CH}_{2}$ and $\mathrm{CH}_{3}$ groups, thus resulting in a characteristic EPR spectrum. The free-radical concentration is directly proportional to the intensity of the EPR signal. ${ }^{12}$ This method was successfully employed in a study of the curing time of visible-light-activated composites as a function of the sample thickness as well as in other investigations involving dental composites. ${ }^{13-16}$

The influence of the free-radical concentration in the underneath composite layer on the effectiveness of the bonding between dental composites has not been investigated yet. Therefore, the aim of our study was to clarify the role of the free-radical concentration on the shear bond strength between two layers of composite using the EPR method and simultaneously to verify the polymerisation process by measuring the DC using Raman spectroscopy.

\section{METHODOLOGY OF THE EXPERIMENTAL WORK}

In order to simulate the cementation process when the IDS technique is used in clinical practice, Filtek Ultimate Flowable Restorative (3M ESPE, St. Paul, MN, USA) was used as the underneath layer and the self-adhesive, dual-cure, Rely X Unicem (3M ESPE, Seefeld, Germany) cement as the freshly applied composite on top of it. The flow composite material was used in accordance with the recommendations, with the IDS technique as the material most appropriate to block out the undercuts of the prepared tooth. The self-adhesive cement Rely X is gaining in popularity among clinicians due to its effectiveness and simplicity of use.

\subsection{Electron paramagnetic resonance (EPR) spectros- copy}

The EPR spectra of the Filtek Ultimate Flowable Restorative composite samples were measured after light activation with a blue-phase G2 LED curing light with an output intensity of $650 \mathrm{~mW} / \mathrm{cm}^{2}$ (Ivoclar Vivadent, Schaan, Liechtenstein) (Figure 1). A relative comparison of the free-radical concentrations in composite samples was obtained by comparing the signal intensities to the same reference EPR sample. We used the so-called "strong pitch" (Bruker GmbH, EPR Division, Rheinstetten, Germany), which is commonly used as a standard sample in EPR spectroscopy for measuring the EPR signal's intensity.

In our study we used a Varian E-9 (Varian, Palo Alto, CA 94303, USA) EPR spectrometer that was partially

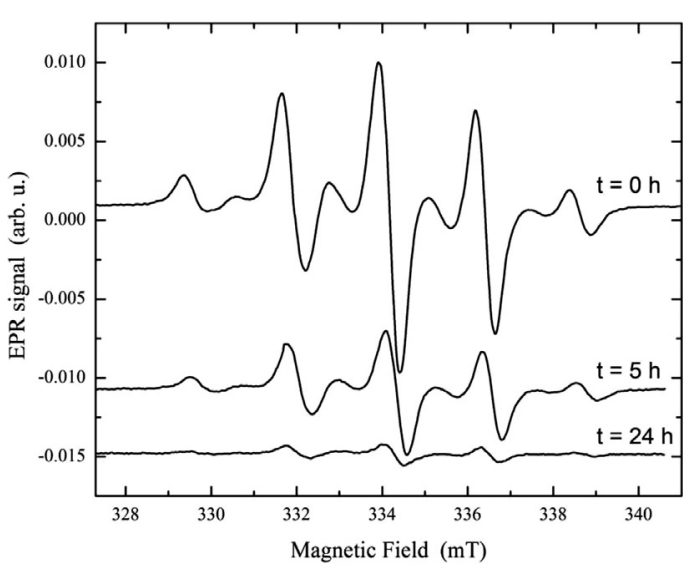

Figure 1: X-band electron paramagnetic resonance (EPR) spectra of methacrylate-based composite measured at ambient temperature immediately after light polymerisation $(t=0), 5 \mathrm{~h}(t=5)$ and $24 \mathrm{~h}(t=24)$ after polymerisation

upgraded. The EPR measurements were performed at an ambient temperature of $20-23{ }^{\circ} \mathrm{C}$. In order to obtain the absolute value of the free radicals, we calibrated the intensity of the composite EPR signal by a comparison with a $\mathrm{CuSO}_{4} \times 5 \mathrm{H}_{2} \mathrm{O}$ standard. We estimated the error of the absolute EPR signal intensity to be around $10 \% .^{12}$

The application of the Filtek Ultimate Flowable Restorative composite using a micro-brush on a quartz plate $(3 \mathrm{~mm} \times 10 \mathrm{~mm})$ produced an approximately 0.15 -mm-thick layer (measured with a digital calliper), which is similar to previous studies that reported thicknesses of 60-80 $\mu \mathrm{m}$ to 200-300 $\mu \mathrm{m}$, respectively, on convex and concave cavity surfaces for an IDS. ${ }^{17}$

The total illumination time was $120 \mathrm{~s}$. Each sample was light activated in 5-second intervals in a cumulative manner. After each illumination the EPR spectrum was recorded and the radical intensity was calculated. ${ }^{12}$ The samples were kept in water at a constant temperature of $37{ }^{\circ} \mathrm{C}$ to promote the recombination of free radicals and were temporarily removed from the water bath for each measurement in order to record the EPR spectrum.

\subsection{Degree of conversion $(D C)$}

Measurements of the Raman spectra were performed on a dispersive Raman spectrometer LabramHR (Horiba Yobin Yvon S.A.S. Molecular \& Microanalysis Division, Villeneuve d'Ascq, France). We selected the spectral region from $1500 \mathrm{~cm}^{-1}$ to $1700 \mathrm{~cm}^{-1}$, where the $\mathrm{C}=\mathrm{C}$ stretching vibrations are expected. Three composite discs, $6 \mathrm{~mm}$ in diameter and $2 \mathrm{~mm}$ thick, from the Filtek Ultimate Flowable Restorative, and a drop of the same non-polymerized composite resin on a glass plate were the samples for the Raman spectra measurements. For every composite disc the Raman scattering was measured at three different spots.

The specimens were excited with red laser light at $\lambda=633 \mathrm{~nm}$ and a low power of between $1 \mathrm{~mW}$ and $10 \mathrm{~mW}$. The spectrum resolution was $1 \mathrm{~cm}^{-1}$. The Raman vibrational modes were found (Figure 2): the stretching mode at $1640 \mathrm{~cm}^{-1}$ is ascribed to the aliphatic 
carbon-carbon double bond $(\mathrm{C}=\mathrm{C})$, as the analytical frequency, while the peak at $1610 \mathrm{~cm}^{-1}$ corresponds to the stretching of the aromatic $\mathrm{C}=\mathrm{C}$ bond, and was used as the reference frequency. The intensities of these two modes were used to determine the DC as follows: the Raman peaks at $1640 \mathrm{~cm}^{-1}$ and $1610 \mathrm{~cm}^{-1}$ were fitted with the Gaussian line shapes to obtain their intensities by integration. The percentage of uncured resin $\mathrm{R}$ was calculated from the ratio of the intensities for the $1640 \mathrm{~cm}^{-1}$ and $1610 \mathrm{~cm}^{-1}$ peaks for the cured and the uncured samples, and finally the DC was calculated as Equation (1):

$$
\mathrm{DC}=100 \times\left[1-\left(\mathrm{R}_{\text {polymerised } /} \mathrm{R}_{\text {unpolymerised }}\right)\right]
$$

\subsection{Shear-bond-strength (SBS) testing}

The composite samples (Filtek Ultimate Flowable Restorative) were prepared directly into the disc-shaped cavities $6 \mathrm{~mm}$ in diameter and $2 \mathrm{~mm}$ thick in acrylic carrier cylinders. The surface was covered with a Mylar strip to minimise the formation of an oxygen-inhibited layer and to form a flat surface, by which the micromechanical interlocking at the bonding interface was reduced to a minimum. To polymerise the composite 40 seconds of light activation was applied. Immediately after the curing of the 10 composite discs (group 1), quartz cylinders with an inner diameter of $3 \mathrm{~mm}$ and a height of $4 \mathrm{~mm}$ were placed on the flat upper surfaces of the discs and carefully filled with the dual-cure, self-adhesive, resin cement Rely X Unicem. The cement was then left to polymerize chemically for 1 hour. Light polymerization was intentionally avoided because we wanted to prevent the eventual creation of additional free radicals within the underneath composite layer. The bonded samples were placed in a water bath at $37{ }^{\circ} \mathrm{C}$ for $24 \mathrm{~h}$. After the quartz cylinders were carefully taken off and the samples were stressed in an Instron testing machine (Instron 4301, Instron Corp., USA) until failure

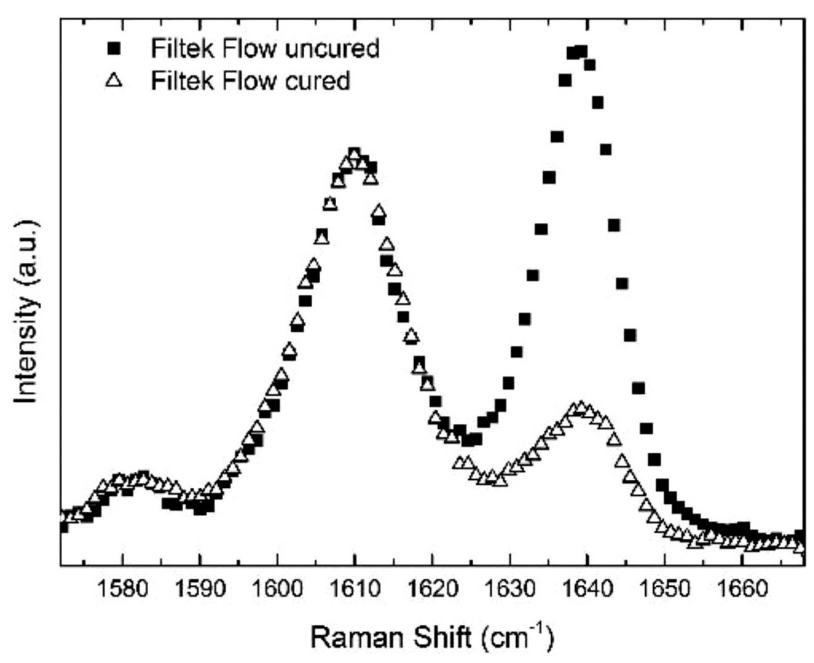

Figure 2: Overlay graph of Raman spectra of cured (triangles) and uncured (squares) Filtec ultimate flowable restorative composite samples at a cross-head speed of $1 \mathrm{~mm} / \mathrm{min}$. The obtained bond strength is expressed in mega Pascals (MPa).

The rest of the three groups of 10 composite sample discs were stored in water at $37{ }^{\circ} \mathrm{C}$ for up to $21 \mathrm{~d}$. Shear bond measurements were performed every $7 \mathrm{~d}$ on 10 different disc samples and the same procedure for the shear-bond evaluation was implemented as previously described for the first group of samples. All together 40 composite discs (4 groups of 10) were used in the study in four different time intervals

\subsection{Microscopic evaluation}

The mode of failure was evaluated using an optical microscope (Stereo Discovery V.8, Carl Zeiss, Germany) at $20 \times$ magnification. The failures were recorded as cohesive (fracture predominantly inside the composite disc) or adhesive (fracture predominantly at the interface between the composite cement and the composite disc).

\subsection{Statistical analysis}

Descriptive statistics, the ANOVA test, and the Bonferoni Post-Hoc test were used to interpret the SBS results in the present study. To compare the cohesive and adhesive failure mode in each time interval an independent t-test was used. For the correlation between the radical concentration and the shear bond strength the Spearman correlation test was used. A $p$ value of $<0.05$ was considered as statistically significant.

\section{RESULTS}

\subsection{Electron paramagnetic resonance $($ EPR) spectros- copy}

The formation of the free radicals as a function of the light activation time in the Filtek Ultimate Flowable Restorative samples with thicknesses of $0.15 \mathrm{~mm}$ is represented by the triangles in Figure 3. The full saturation with free radicals was achieved after $40 \mathrm{~s}$. The concentration was normalized to the saturated value, which was reached after an illumination time of $120 \mathrm{~s}$. The absolute value of the saturated intensity of the EPR signal corresponds to a concentration of $5 \times 10^{18}$ free radicals per $1 \mathrm{~g}$ of composite material.

The recombination dynamics of the free-radical concentration in the thin layer composite is presented as triangles in Figure 4. The normalized radical concentration dropped to $50 \%$ after $5 \mathrm{~h}$ and it further dropped to less than $10 \%$ after $3 \mathrm{~d}$.

\subsection{Degree of conversion}

The DC of the composite increased sharply during the first $40 \mathrm{~s}$ of the illumination to reach a value of $47 \%$. Longer illumination times resulted in a smaller additional increase in the DC, and after $120 \mathrm{~s}$ of illumination the DC only increased to $50 \%$ (Figure 3). During the so-called post-polymerization stage, $2 \mathrm{~d}$ after the 


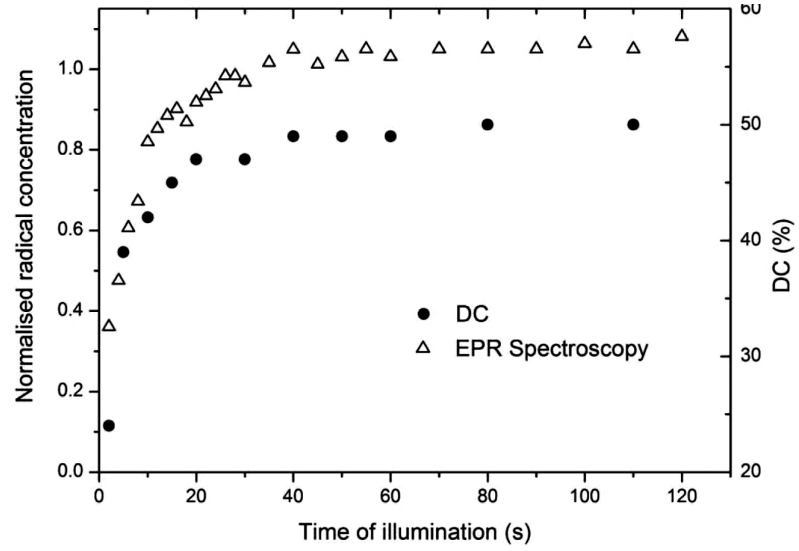

Figure 3: Normalized free-radical concentration measured by electron paramagnetic resonance (EPR) versus time of light activation in Filtek ultimate flowable restorative composite with a thickness of $0.15 \mathrm{~mm}$ (triangles); for comparison, the time dependence of the increase in degree of conversion (DC) after light activation is presented on the same time scale (circles)

illumination of the samples, the DC reached a value of $74 \pm 2 \%$, while changes in the DC were not detected after a longer post-polymerization stage time (Figure 4).

\subsection{Shear bond strength (SBS)}

The SBS measurements for the four sample groups are presented in Figure 5. The mean value for the shear bond strength for the first group of samples with a saturated concentration of free radicals was 25.5 (SD 3.7) MPa. The samples of the second group showed a mean shear bond value of 20.3 (SD 6.7) $\mathrm{MPa}$ after a 7 -day recombination in water at a temperature of $37^{\circ} \mathrm{C}$. After $14 \mathrm{~d}$ of exposure to water the shear bond values of the group 3 samples fell to 16.4 (SD 6.8) $\mathrm{MPa}$. The fourth group of samples exposed to water for $21 \mathrm{~d}$ had shear bond values of 9.8 (SD 4.3) MPa.

The ANOVA test was used to reveal the statistically significant differences between the shear bond strengths

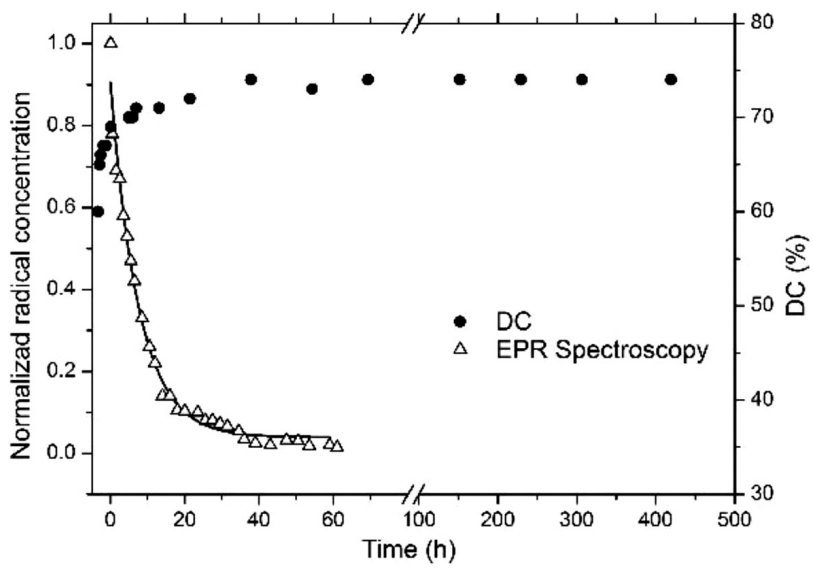

Figure 4: Recombination of normalized free-radical concentration in the Filtek ultimate flowable restorative composite in water (triangles); the degree of conversion (DC) values of samples exposed to water bath are presented on the same time scale (circles)

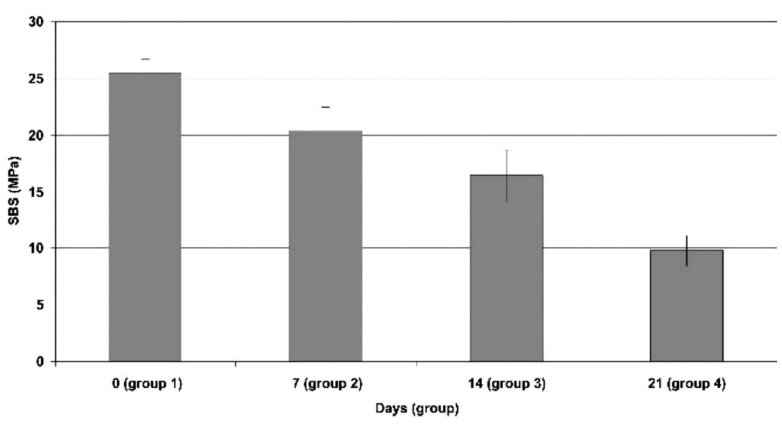

Figure 5: The Shear bond strength values of four groups of composite samples in different time intervals

of the samples. It was estimated that there is a statistically significant difference between the samples from group 1 to group $4(p=0.001)$. The post-hoc Bonferroni test confirmed there were statistically significant differences between group 1 with the saturated free radical concentration and group $3(p=0.006)$ and group $4(p=$ $0.001)$, a statistically significant difference was also found between groups 2 and $4(p=0.001)$.

The Spearman correlation test showed that the correlation between the radical concentration and the shear bond strength was approaching statistical significance $(p=0.051)$

\subsection{Failure mode}

All the samples of group 1 with a high concentration of free radicals failed cohesively in the underneath composite, while most of the samples $(80 \%)$ in group 4 failed adhesively. The failure modes in groups 2 and 3 had a progressive drop in the cohesive mode of failure from $80 \%$ to $56 \%$.

\section{DISCUSSION}

During the adhesive cementation of the indirect restoration to the etched enamel and with IDS protected dentine, which is commonly 1 to 3 weeks after the initial appointment, we strive to achieve good bonding between the two composite materials. The micro-tensile bond strengths between the composite and the bur-cut enamel and dentine covered by different bonding agents or using different treatment times are in the range from 3.2 MPa to $49.5 \mathrm{MPa}$ for the enamel and between $15.5 \mathrm{MPa}$ and 63.1 MPa for the dentin. ${ }^{18-21}$ On the other hand, the bond strength between the two dental composite surfaces can be in the range between $5.7 \mathrm{MPa}$ and $44.7 \mathrm{MPa}$, depending on how the surfaces are prepared and the application of different adhesion primers. ${ }^{10,22,23}$ It is assumed, but has never been directly proven, that the free radicals in the underneath layer are responsible for the successful bonding with the monomers from a subsequently applied composite layer. ${ }^{3,4,10}$

For now it is not possible to isolate precise data for the concentration of the free radicals at the bonding 
surface that are involved in the chemical bonding between two layers of composite.

Assuming that the free radicals in the thin superficial layer are responsible for bonding of new applied composite cement, we did not examine the creation and decay of free radicals in bulk samples, but in a 0.15 -mm-thin layer of composite resin.

In view of the reported life span for the free radicals of up to 4-5 weeks, some authors indirectly presume that a period of 1-2 weeks would still provide a sufficient concentration of free radicals within the existing resin coating for a reliable bond with the newly applied layer. ${ }^{4}$ Other authors supposed that the free-radical decay is an even slower process and assumed the presence of free radicals that are suitable for a subsequent reaction in the composite substrate aged for up to 12 weeks. ${ }^{24}$ However, a study employing EPR spectroscopy revealed that the half-life of the free radicals in bulk samples $(25 \times 2 \times 2) \mathrm{mm}$ of composites at $37{ }^{\circ} \mathrm{C}$ is $2-5$ days. ${ }^{3}$

The observed discrepancy between our results regarding the time-dependent decay of free-radicals and those in the literature is understandable if we take into account that we have made measurements on 0.15-mm-thick samples, while other authors report the sample thickness to be $2-3 \mathrm{~mm}$, and consequently the diffusion processes involved in the radical termination take a longer time. ${ }^{3}$

A supplementary experiment with Raman spectroscopy confirms that the polymerization process after the illumination continues and the polymer becomes stable after $48 \mathrm{~h}$, which is in accordance with a previous study. ${ }^{25}$ The DC sharply increased in the first $40 \mathrm{~s}$ of illumination until it reached a value of $47 \%$, when the polymerization slowed down owing to the low mobility of the monomers in a formed polymer network. Illumination for $120 \mathrm{~s}$ resulted in a DC increase to the value of $50 \%$. The diameter of the laser's focus spot sphere in the Raman experiment was estimated to be 10 micrometers. Therefore, both the DC and free-radical concentration measurements provided data from the thin layers. Free radicals are formed during the illumination, they undergo polymerization, at which time they are consumed very rapidly. With increasing DC values at higher illumination times and with the polymerization slowing down, the free-radicals are not consumed regularly and the concentration of free radicals is increasing until it saturates (Figure 3).

In our experiment the free-radical concentration decreased in the post-illumination period, while the DC continued to increase, which is in accordance with the findings of J. Leprince. ${ }^{26}$ This is affected by the post polymerization and additionally with monomer elution as well as with hydrolytical degradation, at least in the topmost layers of the composites samples that were immersed in water after the illumination process. ${ }^{27,28}$

Previous studies do not provide a direct explanation for the influence of the remaining free-radical concen- tration in the aged composite about its bonding capability with freshly applied material. ${ }^{24}$ Our study revealed that the high concentration of the free radicals in the underneath layer can provide reliable chemical bonding to the overlaid substrate. This enables both layers to act as a unit, which was confirmed by the $100 \%$ cohesive failures of the samples from the first group.

This means that in the initial phase, the bonding between the composite and the composite cement, in particular, depends on the chemical interactions of the active free radicals of the two composite materials in contact. It could be expected that along with a recombination of free radicals, the capacity of the bonding between the two materials would decrease.

However, high shear-bond-strength measurements obtained in our experiment and the cohesive failure mode indicate that the concentration of free radicals has an impact on the SBS values only in the case of composite cement being applied to the freshly polymerised composite in the thin layer. Despite the relatively fast decrease of free-radical concentration (Figure 4), the SBS values in groups 2, 3 and 4 do not follow the dynamics of free-radical decay (Figure 5).

The radical concentration decreased to less than $10 \%$ of the initial concentration after $3 \mathrm{~d}$, while the number of cohesive failures after $7 \mathrm{~d}$ (group 2) decreased by only $20 \%$. We can conclude that the free radicals play an important role in improving the strength of the bonding in the initial phase of the layer formation, whereas later on, the bonding between the old and the new composite is also ensured by other mechanisms, e.g., an interpenetrating network..$^{11,29}$

The limitation of our study is that we used only one flow composite material and one composite cement. Maybe the radical decay in other brands of flow material is different and consequently the results would not be the same. However, we intentionally used the two materials produced by the same company to be as precise as possible in the results and conclusions. On the other hand, EPR spectroscopy detects the free radicals in the entire composite sample and not only at the bonding surface that is involved in the experiment.

\section{CONCLUSIONS}

The concentration of the free radicals in the fresh composite provides reliable chemical bonding to the newly applied layer. Measurements of the free-radical concentration in a thin layer of composite show a relative high decay rate; therefore, the influence of the underneath layer on the chemical bonding between two composite materials is high only in the initial phase after polymerization. The low free-radical concentration present within the composite substrate aged for 1, 2 and 3 weeks does not ensure chemical bonding to an overlaid, freshly applied composite. 
Clinically acceptable bonding between the old and the new composite is ensured by other mechanisms that are less dependent on the free radicals in the underlying composite.

\section{Acknowledgement}

The authors gratefully acknowledge the financial support from the Slovenian Research Agency (research core funding No. P2-0145 and P1-0045).

\section{REFERENCES}

${ }^{1}$ S. J. Paul, P. Schärer, The dual bonding technique: a modified method to improve adhesive luting procedures, International Journal of Periodontics \& Restorative Dentistry, 17 (1997) 6, 536-545, doi: $10.11607 /$ prd.00.0243

${ }^{2} \mathrm{P}$. Magne, Immediate dentin sealing: a fundamental procedure for indirect bonded restorations, Journal of Esthetic and Restorative Dentisty, 17 (2005) 3, 144-154, doi:10.1111/j.1708-8240.2005. tb00103.x

${ }^{3} \mathrm{P}$. Burtscher, Stability of radicals in cured composite materials, Dental Materials, 9 (1993) 4, 218-221, doi:10.1016/0109-5641(93) 90064-W

${ }^{4}$ S. Dall'Oca, F. Papacchini, C. Goracci, A. H. Cury, B. I. Suh, F. R. Tay, A. Polimeni, M. Ferrari, Effect of oxygen inhibition on composite repair strength over time, Journal of Biomedical Materials Research Part B: Applied Biomaterials, 81 (2007) 2, 493-498, doi:10.1002/jbm.b.30689

${ }^{5}$ U. Lohbauer, M. Pelka, R. Belli, J. Schmitt, E. Mocker, K. D. Jandt, F. A. Müller, Degree of conversion of luting resins around ceramic inlays in natural deep cavities: A micro-Raman spectroscopy analysis, Operative Dentistry, 35 (2010) 5, 579-586, doi:10.2341/10012-L

${ }^{6}$ M. Ozcan, G. Pekkan, Effect of delay layering on the incremental adhesion of indirect dental composite resins, International Journal of Adhesion and Adhesives, 39 (2012) 15-20, doi:10.1016/j.ijadhadh. 2012.06.008

${ }^{7}$ F. C. Calherios, Y. Kawano, J. W. Stansbury, R. R. Braga, Influence of radiant exposure on contraction stress, degree of conversion and mechanical properties of resin composites, Dental Materials, 22 (2006) 9, 799-803, doi:10.1016/j.dental.2005.11.008

${ }^{8}$ X. Meng, K. Yoshida, M. Atsuta, Influence of ceramic thickness on mechanical properties and polymer structure of dual-cured resin luting agents, Dental Materials, 24 (2008) 5, 594-599, doi:10.1016/ j.dental.2007.06.014

${ }^{9}$ R. Van Noort, Introduction to dental materials, $3^{\text {rd }}$ ed. Elsevier, Edinburgh 2007, 99-126, doi:10.1038/sj.bdj.2013.734

${ }^{10}$ F. Papacchini, S. Dall'Oca, N. Chieffi, C. Goracci, F. T. Sadek, B. I. Suh, F. R. Tay, M. Ferrari, Composite-to-composite microtensile bond strength in the repair of a microfilled hybrid resin: effect of surface treatment and oxygen inhibition, Journal of Adhesive Dentistry, 9 (2007) 1, 25-31, doi:10.3290/j.jad.a11966

${ }^{11}$ L. H. Sperling, D. Klempner, Advances in Chemistry, Interpenetrating polymer networks: an overview, American Chemical Society, Washington DC, 1994, 3-38, doi:10.1021/ba-1994-0239.ch001

${ }^{12}$ G. R. Eaton, S. S. Eaton, D. P. Barr, R. T. Weber, Quantitative EPR, Springer-Verlag, Wien, New York 2010, doi:10.1007/978-3-21192948-3

${ }^{13}$ A. da Silva Fontes, W. Sano, L. H. Dall'Antonia, E. Di Mauro, EPR in the characterization of the shade effect on translucence, remaining free radicals, and polymerization depth of commercially available resin composites, Applied Magnetic Resonance, 39 (2010) 4, 381-390, doi:10.1007/s00723-010-0172-6

${ }^{14}$ G. Lamblin, J. Leprince, J. Devaux, M. Mestdagh, B. Gallez, G. Leloup, Hydroxyl radical release from dental resins: electron paramagnetic resonance evidence, Acta Biomaterialia, 6 (2010) 8, 3193-3198, doi:10.1016/j.actbio.2010.03.001

${ }^{15}$ J. G. Leprince, P. Leveque, B. Nysten, B. Gallez, J. Devaux, G. Leloup, New insight into the "depth of cure" of dimethacrylate-based dental composites, Dental Materials, 28 (2012) 5, 512-520, doi:10.1016/j.dental.2011.12.004

${ }^{16}$ D. Sustercic, P. Cevc, N. Funduk, M. M. Pintar, Determination of curing time in visible-light-cured composite resins of different thickness by electron paramagnetic resonance, Journal of Material Science Materials Medicine, 8 (1997) 8, 507-510, doi:10.1023/ A: 1018534428200

${ }^{17}$ M. M. Stavridakis, I. Krejci, P. Magne, Immediate dentin sealing of onlay preparations: Thickness of pre-cured dentin bonding agent and effect of surface cleaning, Operative Dentistry, 30 (2005) 6, 747-757, doi:10.2341/04-151

${ }^{18}$ J. De Munck, B. Van Meerbeek, I. Satoshi, M. Vargas, Y. Yoshida, S. Armstrong, P. Lambrechts, G. Vanherle, Microtensile bond strengths of one- and two-step self-etch adhesives to bur-cut enamel and dentin, American Journal of Dentistry, 16 (2003) 6, 414-20

${ }^{19}$ S. Inoue, M. A. Vargas, Y. Abe, Y. Yoshida, P. Lambrechts, G. Vanherle, H. Sano, B. Van Meerbeek, Microtensile bond strength of eleven contemporary adhesives to enamel, American Journal of Dentistry, 16 (2003) 5, 329-334

${ }^{20}$ S. Inoue, M. A. Vargas, Y. Abe, Y. Yoshida, P. Lambrechts, G. Vanherle, H. Sano, B. Van Meerbeek, Microtensile bond strength of eleven contemporary adhesives to dentin, Journal of Adhesive Dentistry, 3 (2001) 3, 237-245

${ }^{21}$ N. S. Kimmes, W.W. Barkmeier, R. L. Erickson, M. A. Latta, Adhesive bond strengths to enamel and dentin using recommended and extended treatment times, Operative Dentistry, 35 (2010) 1, 112-119, doi:10.2341/09-081-L

${ }^{22}$ M. Ozcan, P. Alander, P. K. Vallitu, M. C. Huysmans, W. Kalk, Effect of three surface conditioning methods to improve bond strenght of particulate filler resin composites, Journal of Material Science Materials Medicine, 16 (2005) 1, 21-27, doi:10.1007/ s10856-005-6442-4

${ }^{23}$ A. Tezvergil, L.V. J. Lassila, P. K. Vallittu, Composite-composite repair bond strenght: effect of differnt adhesion primers, Journal of Dentistry, 31 (2003) 8, 521-525, doi:10.1016/S0300-5712(03) 00093-9

${ }^{24}$ P. Magne, W. S. So, D. Cascione, Immediate dentin sealing supports delayed restoration placement, Journal of Prosthetic Dentistry, 98 (2007) 3, 166-174, doi:10.1016/S0022-3913(07)60052-3

${ }^{25}$ V. Miletic, A. Santini, Micro-Raman spectroscopic analysis of the degree of conversion of composite resins containing different initiators cured by polywave or monowave LED units, Journal of Dentistry, 40 (2012) 2, 106-113, doi:10.1016/j.jdent.2011.10.018

${ }^{26}$ J. Leprince, G. Lamblin, D. Truffier-Boutry, S. Demoustier, Champagne, J. Devaux, M. Mestdagh, G. Leloup, Kinetic study of free radicals trapped in dental resins stored in different environments, Acta Biomaterialia, 5 (2009) 7, 2518-2524, doi:10.1016/j.actbio. 2009.04.034

${ }^{27}$ J. L. Ferracane, Elution of leachable components from composites, Journal of Oral Rehabilitation, 21 (1994) 4, 441-452, doi:10.1111/ j.1365-2842.1994.tb01158.x

${ }^{28}$ J. L. Ferracane, Hygroscopic and hydrolitic effects in dental polymer networks, Dental Materials, 22 (2006) 3, 211-222, doi:10.1016/ j.dental.2005.05.005

${ }^{29} \mathrm{P}$. K. Vallittu, Interpenetrating poymer networks (IPNs) in dental polymers and composites, Journal of Adhesion Science and Technology, 23 (2009) 7-8, 961-972, doi:10.1163/156856109X432785 